\title{
Bio Informatics in private universities in India: An Emerging Study on promotion of Biological Information Sciences
}

\author{
P. K. Paul1, P. S. Aithal2 \\ ${ }^{1}$ Raiganj University (RGU), West Bengal, India \\ ${ }^{2}$ Vice Chancellor, Srinivas University, Karnataka, India
}

Corresponding Author: pkpaul.infotech@gmail.com

\begin{abstract}
Information Science is an interdisciplinary domain and plays a great role in the development at large. Information Science and Informatics normally treated as a synonym in academia worldwide. Information Science/Informatics is an applied science branch and thus with the combination of other areas and subject created many other knowledge cluster and field viz. Geo Information Science, Chemo Information Sciences, Environmental Information Science. Bio Information Sciences may be considered as a field of intersection of Biology and Information Science. Bio Informatics may be treated as one of the areas of Bio Information Sciences. Indian universities moving towards education, training, and research in interdisciplinary fields and as a result Bio related Informatics become vital. Higher Educational Institution's number wise India also holds a rank in the world. In recent past private universities expanded rapidly. Many of them started offering Bio Informatics program in different level of study. This is a theoretical framework in terms of research paper and here several knowledge on information sciences, informatics with reference to Bio Informatics have been provided. The paper also highlighted emerging other allied areas including future potentialities in brief.
\end{abstract}

\section{Keywords}

Informatics, Information Science, Bio Sciences, Bio Informatics, Health Informatics, Interdisciplinary Science.

\section{Introduction}

Informatics is a study and practice of information affairs viz. collection, selection, organization, process, managing, and dissemination. For such information affairs Informatics employ various kinds of tools and technologies like database technologies, network technologies, web technologies, and multimedia technologies. Informatics in comparison with IT also deals with information affairs and studies related to the information and knowledge management. The increasing need and applicability of Informatics in divers fields and areas have created many other domains and among them most popular and useful are Bio Informatics, Geo Informatics, 
Eco Informatics, Health Informatics etc [1], [5]. It is important to note that these domains are also known and nomenclature with Information Science (e.g. Health Information Science). Bio Information Sciences may be treated as broad domains with interconnection of Bio Sciences with Informatics/IT hence among its sub fields and allied fields popular are Bio Informatics, Health Informatics, and Eco Informatics. Initially, the Bio Informatics field in India offered in the State Universities and its affiliating universities but gradually the situation has been changed. Due to the initiation of private universities many now are offering program in this field. However it is worthy to mention that still the full-fledged programs on Informatics in India (like IT/CSE offered with BSc/MSc/BTech/MTech) not visible. Though few are started operation. Bio Informatics has its significance in different areas of biology including pharmaceutical sciences. Few of the Indian universities are offering the program with industrial components as well [2], [3], [10].

\section{Objectives \& Agenda}

The core aim and agenda of this conceptual, framework based paper include the following (should not be confused with only these) -

- To learn about the basic of Informatics and Information Sciences including its nature, features and areas.

- To dig out the core as well as sub fields of Informatics with emerging areas in brief manner.

- To learn about the Biological focus of Informatics with reference to Bio Informatics including its function, features, and role in concise manner.

- To dig out the emerging concept and Bio Information Sciences with reference to programs and degrees available in the field.

- To learn about the private universities in India with reference to other Higher Educational Institutes in brief.

- To learn about the current challenges, issues, and future potentialities of offering Informatics programs in India.

\section{Methodology}

The paper is purely framework on Informatics domain with emphasis on its educational opportunities in India. Thus, as a research based study firstly the review of literature has been adopted and studied. Later web review has also been undertaken to learn about the latest on Informatics in Indian Universities and thus the UGC site on universities has been selected to reach every private university in India. The compilation of book review, web review, and university based specific study lead the conceptual framework. All the primary sources later analyzed and reported in this conceptual research work. As it has potentiality in policy framing and thus case study methods also been adopted and the report presented in such a way. 


\section{Informatics and Informatics as a branch}

Informatics is an interdisciplinary branch of study responsible for information affairs dedicated for the collection, selection, organization, processing, management, and dissemination. Though the academic area called Information Studies also deals with the same subject but additionally, Informatics lies on technologies for its operation viz. Computing Technology, Networking Technology, Database Technology, Web Technology, Multimedia Technology etc [4], [9], [10].

Informatics thus also associated with the management tools, techniques, and principles for managing contents, information, and knowledge. Informatics initially was treated as a tool and concept but gradually the requirement leads as a domain/ subject 'Informatics' [5], [6], [9]. Many universities around the world offer Informatics program as a Bachelors, Masters, and Doctoral program of study. It is normally offered with BSc/ MSc/PhD Degree. However, it is important to note that except few universities all these are offering the program as full-fledged degrees rather specialization in other allied degrees [7], [8], [11].

Gradually the need of Informatics in other branches and areas led the promotion and development of new branches and subjects (refer Table: 1 for details).

Table: 1 Evolution of Informatics branch

\begin{tabular}{|c|c|}
\hline Combination of Subjects & Subject Evolved \\
\hline Biology with Informatics/IS & Bio Informatics \\
\hline Chemical Sciences with Informatics/IS & Chemo Informatics \\
\hline Social Sciences with Informatics/IS & Social Informatics \\
\hline Environment with Informatics/IS & $\begin{array}{c}\text { Environmental Informatics } \\
\text { Eco Informatics }\end{array}$ \\
\hline Health Sciences with Informatics/IS & Health Informatics \\
\hline $\begin{array}{c}\text { Pharmaceutical Sciences with } \\
\text { Informatics/IS }\end{array}$ & Pharma Informatics \\
\hline Geo Sciences with Informatics/IS & Geo Informatics \\
\hline Quantum Sciences with Informatics/IS & Quantum Informatics \\
\hline Medical Sciences with Informatics/IS & Medical Informatics \\
\hline
\end{tabular}

The development of Computing and Informatics including its requirement led the evolution and requirement of other branches in developing countries as well. In developing country like India as well in recent past many universities have started domain specific Informatics mainly Bio Informatics. The details on Indian knowledge delivery offered in India provided in the sections later.

\section{Bio Information Sciences: A Foundation}


Bio Informatics is a study and practice of biological information into computerization and uses of information technology tools, technologies. Bio Informatics is a combination of biological affairs and information technological integration [9], [12].

In generally Bio Informatics may be defined as similar to the Bio Information Technology but it is more than that and also includes traditional information management, knowledge management and organizational tools for the manual bio related information affairs and largely documentation. Life sciences organizations, bio technology establishment, and companies are using Bio Informatics programs and degrees [11], [13].

In generally applications of programming languages viz. C, C++, Java, Perl, and Python treated as a vital programming language for the bio related affairs. Though Database and Database Management Systems (DMBS) also play a great role in the creation of design, development of biological repositories. Computing Networks is also partially used in Bio Informatics for the collaboration, cooperation, and research promotion in Bio Informatics and allied branches [6], [10], [14].

\section{Indian Higher Education and Private Universities}

India is moving towards the promotion of higher education, research, and training. Today many organizations, institutions, and association are closely working with universities for the solid promotion of university's affairs. India is going to reach its developed tag soon and thus in recent past many universities have established various tag namely

- Private Universities

- Public Universities

- Deemed Universities

- Institute of National Importance (INI)

As a whole combining all the universities India holds total 40000+ Higher Educational Institutes (HEIs). Private Universities recently have emerged with great extent most of the State except few viz. Telangana, Kerala, Tamilnadu. A detailed report on private universities has listed in Table: 2 .

Table: 2- Private Universities of India at a glance

\begin{tabular}{|c|l|c|}
\hline Serial No. & \multicolumn{1}{|c|}{ States } & No. of Universities \\
\hline 1 & Arunachal Pradesh & 7 \\
\hline 2 & Assam & 5 \\
\hline 3 & Bihar & 2 \\
\hline 4 & Chhattisgarh & 9 \\
\hline 5 & Gujarat & 30 \\
\hline 6 & Haryana & 20 \\
\hline 7 & Himachal Pradesh & 17 \\
\hline 8 & Jharkhand & 7 \\
\hline
\end{tabular}




\begin{tabular}{|c|l|c|}
\hline 9 & Karnataka & 14 \\
\hline 10 & Meghalaya & 8 \\
\hline 11 & Mizoram & 1 \\
\hline 12 & Madhya Pradesh & 24 \\
\hline 13 & Maharashtra & 9 \\
\hline 14 & Manipur & 3 \\
\hline 15 & Nagaland & 4 \\
\hline 16 & Odisha & 15 \\
\hline 17 & Punjab & 46 \\
\hline 18 & Rajasthan & 5 \\
\hline 19 & Sikkim & 1 \\
\hline 20 & Tripura & 29 \\
\hline 21 & Uttar Pradesh & 13 \\
\hline 22 & Uttrakhand & 9 \\
\hline 23 & West Bengal & 279 \\
\hline & $\quad$ Grand Total & \\
\hline
\end{tabular}

\section{Informatics and Emerging Trends}

Informatics is an applied science gained popularity from 2000 in India and many universities worldwide have started diverse branches of Informatics. Among the popular branches, few important are include-

- Bio Informatics

- Health Informatics

- Environmental informatics

- Forest informatics

- Geo informatics

- Nero Informatics

- Dental Informatics

- Nursing Informatics

However, as far as this study is concerned most of the private universities offering programs related to the Informatics is Bio Informatics. While few others have been started programs Telecom Informatics, Health Informatics, Geo Informatics (refer Table: 6). It is worthy to note that in India general Informatics is still absent in India except Galgotias University, UP, University of Petroleum and Energy Studies, UK.

\section{Informatics and Bio Sciences: The rising context}

Informatics in some countries called as Information Science. Hence in such context, Bio Informatics may be defined as Bio Information Science. However, in context of Bio Sciences 
(including Informatics) the branch may be considered as Bio Informatics, Health Informatics, and partially Geo Informatics. The branch Bio Informatics is available mainly as Masters Degree in private universities in India. However, few universities offer Bachelor programs in Informatics and as per the study BTech is the main program and one program with BSc. Importantly all these are directly or full-fledged Bio Informatics programs (Table: 3 provides details of the programs).

Table: 3 Bio Informatics with BSc/ BTech Program.

\begin{tabular}{|c|c|c|}
\hline Sl. No. & Universities & UG \\
\hline $\mathbf{1}$ & Amity University, Gurgaon & BTech (Bio Informatics) \\
\hline $\mathbf{2}$ & SRM University, NCR & BTech-(Bio Informatics) \\
\hline $\mathbf{3}$ & $\begin{array}{c}\text { Jaypee University of Information } \\
\text { Technology, HR }\end{array}$ & BTech-(Bio Informatics) \\
\hline $\mathbf{4}$ & Jaipur National University, Rajasthan & BSc-Bio Informatics \\
\hline
\end{tabular}

Among the universities offering Bachelors in Bio Informatics all are reputed player viz. Amity University, Gurgaon, SRM University, NCR, Jaypee University of Information Technology, HR. However, Masters level Bio Informatics offered by total 8 (eight) universities. Among the private player major are Shridhar University, Rajasthan, Galgotias University, Uttar Pradesh, The Neotia University, West Bengal. Table: 4 provide a detailed overview of the program.

Table: 4 Post Graduate program on Bio Informatics in Private Universities

\begin{tabular}{|c|c|c|}
\hline Sl. No. & Universities & UG \\
\hline $\mathbf{1}$ & Jaipur National University, Rajasthan & MSc-Bio Informatics \\
\hline $\mathbf{2}$ & $\begin{array}{c}\text { Mody University of Science and Technology, } \\
\text { Rajasthan }\end{array}$ & $\begin{array}{c}\text { PGD } \\
\text { in Bio Informatics }\end{array}$ \\
\hline $\mathbf{3}$ & Shridhar University, Rajasthan & MSc-Bio Informatics \\
\hline $\mathbf{4}$ & Singhania University, Rajasthan & MSc-Bio Informatics \\
\hline $\mathbf{5}$ & Galgotias University, Uttar Pradesh & MSc-Bio Informatics \\
\hline $\mathbf{6}$ & IFTM University, Uttar Pradesh & MTech- Bio Informatics \\
\hline $\mathbf{7}$ & Maharishi University of Information Technology, & MSc-Bio Informatics \\
\hline $\mathbf{8}$ & Uttar Pradesh & $\begin{array}{c}\text { Integrated MSc-Bio Tech } \\
\text { \& Bio Informatics }\end{array}$ \\
\hline
\end{tabular}

Among the program on Bio Informatics offered by the private universities, The Neotia University (TNU), West Bengal offers an integrated program for 10+2 holders and importantly apart from Bio Informatics it is also offered Bio Technology as Integrated MSc in Bio-Tech \& Bio Informatics.

Informatics with another focus is available as Health Informatics within the category of Bio Information Sciences. This is previously offered only by the Deemed Universities (viz. Amrita, 
Manipal) but the development of private universities initiated such Health Informatics program also as Bachelors and Masters Program as shown in Table: 5.

Table: 5 Health Informatics in Private Universities

\begin{tabular}{|c|c|c|c|}
\hline \multirow[t]{2}{*}{ Sl. No. } & \multicolumn{3}{|c|}{ Health Informatics at Private Universities } \\
\hline & Universities & UG & PG \\
\hline 1 & $\begin{array}{c}\text { University of } \\
\text { Petroleum and Energy } \\
\text { Studies, UK }\end{array}$ & $\begin{array}{c}\text { BTech (H)-CSE } \\
\text { (Health Informatics) }\end{array}$ & - \\
\hline 2 & $\begin{array}{c}\text { Institute of Trans- } \\
\text { Disciplinary Health } \\
\text { Sciences and } \\
\text { Technology University }\end{array}$ & - & $\begin{array}{l}\text { Integrated MSc-CS } \\
\text { (Health Informatics) }\end{array}$ \\
\hline 3 & $\begin{array}{c}\text { Chitkara University, } \\
\text { Punjab }\end{array}$ & - & $\begin{array}{l}\text { MBA (Health IT) with } \\
\text { Fortis }\end{array}$ \\
\hline 4 & $\begin{array}{c}\text { Mahatma Gandhi } \\
\text { University of Medical } \\
\text { Sciences \& } \\
\text { Technology, Rajasthan }\end{array}$ & BSc-Health Informatics & $\begin{array}{l}\text { PGD Nursing Informatics } \\
\text { PGD Health Informatics } \\
\text { MSc-Health Informatics }\end{array}$ \\
\hline
\end{tabular}

The Mahatma Gandhi University of Medical Sciences \& Technology, Rajasthan offers the highest number of programs in Health Information Science segment with BSc, MSc and Post Graduate Diploma.

Health Informatics is the application of Information Technologies and Computing in Health Sciences which include healthcare settings, hospitals, medical affairs, clinical establishment and so on. As far as allied and sub field of Health Informatics are concerned popular branches are Dental Informatics, Nero Informatics, Medical Informatics, and Nursing Informatics. Among the universities Nursing Informatics is being offered by the Mahatma Gandhi University of Medical Sciences \& Technology, Rajasthan with Post Graduate Diploma.

Table: 6 Geo Informatics in Private Universities

\begin{tabular}{|c|c|c|}
\hline Sl. No. & Universities & PG \\
\hline $\mathbf{1}$ & Himalayan University, Arunachal Pradesh & MSc (Geo Informatics) \\
\hline $\mathbf{2}$ & Pragyan International University & MSc (Geo Informatics) \\
\hline $\mathbf{3}$ & Sangam University, Rajasthan & MSc (Geo Informatics) \\
\hline $\mathbf{4}$ & Sikkim Manipal University, Sikkim & PGD in Geo Informatics \\
\hline $\mathbf{5}$ & Amity University, Uttar Pradesh & MTech-Geo Informatics \\
\hline
\end{tabular}

Health Informatics is now available with the BTech level as a specialization; this is most important and valuable aspects of higher education segment as far as Health Informatics is concerned. Importantly two universities started Health Informatics with Computer Science 
specialization. Apart from BTech segment, Health Informatics is also offered with the Management degree called MBA. Chitkara University, Punjab started MBA in Health IT and this is a significant move on Health Informatics branch promotion in India.

It is worthy to note that private universities are also offering another bio focused Informatics branch called Geo Informatics and the details are provided in Table: 6.

\section{Suggestion and Direction}

Interdisciplinary research is the pillar for development of any kind. Government, society, business, and commerce today many ways depends on research and especially interdisciplinary in nature. It is worthy to note that in recent past a large number of universities have been established with private funding. They have started a good number of initiatives in the promotion of interdisciplinary research and as a result, the branch called Bio Informatics gained popularity. Earlier only state universities and few central universities were the stakeholders in promotion of Bio Informatics field and gradually deemed and private universities become a vital place for the promotion of interdisciplinary research and upcoming branch of Bio Information Sciences.

Though India already started a good number of initiatives in Bio Information Sciences promotion but still it is important to initiate other valuable and demanding/ possible programs viz. in Management Segment BBA/MBA may be started with Bio Informatics specialization. The same may be started in BBA in Health Informatics.

Health Informatics already started with BTech-CSE specialization (though it is for evaluation, designing, and development of Computing tools/ technologies/ systems) but the same may be started directly as BTech/MTech-Health Informatics. Though the specialization methods may also be chosen under the stream IT as it is dedicated for the use and integration of Computing and Information Technologies for information affairs and thus the same may be deployed in Healthcare sector. Similarly, Bio Informatics branch may be started with the specialization of BTech/MTech with Information Technology program.

\section{Conclusion}

Finance and budget is an important facet of the development of any branch of education. Progress of education, research and training thus highly depends on proper funding by private or public sectors. It is important to note that most of the universities noted here private sector and few others are also moving from deemed universities though there are huge potentialities waiting from Government universities. All the programs fall under the Bio Information Sciences professional in nature hence it is better to prepare curricula keeping industries in mind. Moreover industrial tie-ups are always better for designing and development of skilled manpower. The development in healthcare segment is noticeable and private players are moving towards more modernization hence in this regard it is better to initiate program in collaboration with the industry and organizations. 


\section{References}

[1] Ditty, J. L., Kvaal, C. A., Goodner, B., Freyermuth, S. K., Bailey, C., Britton, R. A., \& Sanders-Lorenz, E. R. (2010). Incorporating genomics and bioinformatics across the life sciences curriculum. PLoS biology, 8(8).

[2] Eysenbach, G. (2000). Consumer health informatics. British medical journal, 320(7251), 1713.

[3] Faith, D. P., \& Baker, A. M. (2006). Phylogenetic diversity (PD) and biodiversity conservation: some bioinformatics challenges. Evolutionary bioinformatics online, 2, 121.

[4] Haux, R. (1997). Aims and tasks of medical informatics. International journal of medical informatics, 44(1), 920.

[5] Hersh, W. R., Junium, K., Mailhot, M., \& Tidmarsh, P. (2001). Implementation and evaluation of a medical informatics distance education program. Journal of the American Medical Informatics Association, 8(6), 570584.

[6] Hook, S. A. (2003). Teaching health informatics: designing a course for a new graduate informatics program. Journal of the Medical Library Association, 91(4), 490.

[7] Kun, L. G. (2001). Telehealth and the global health network in the 21 st century. From homecare to public health informatics. Computer methods and programs in biomedicine, 64(3), 155-167.

[8] Maloney, M., Parker, J., LeBlanc, M., Woodard, C. T., Glackin, M., \& Hanrahan, M. (2010). Bioinformatics and the undergraduate curriculum. CBE-Life Sciences Education, 9(3), 172-174.

[9] Martin, S.B. (1998). Information technology, employment, and the information sector: Trends in information employment 1970-1995. Journal of the American Society for Information Science, 49(12), 1053-1069.

[10] Pau1, P.K., Ashok Kumar, Dipak Chaterjee (2012) “ Health Informatics and its Practice: Emerging Domain of Information Science-Indian Scenario” in Current Trends in Biotechnology and Chemical Research, 2 (2), 8387.

[11] Pau1, P.K., D Chatterjee, M Ghosh (2012). Medical Information Science: Emerging Domain of Information Science and Technology (IST) forsophisticated Health \& Medical Infrastructure Building — An Overview. International Scientific Journal of Sports Science, 1 (2), -104.

[12] Pau1, P.K., J. Ganguly, M Ghosh, (2013). Medical Information Science: Overview and a model curriculum of MSc-Information Science [Medical Information Science]. Submitted for Current Trends in Biotechnology and Chemical Research, 3 (1), 50-54 .

[13] Pau1, P.K., (2013). Web 2.0 and Social Networking in Pharmacy and Allied Medical Domain: An overview. International Journal of Marketing Theory, 3 (2), 137-143.

[14] Williams, J. J., \& Teal, T. K. (2017). A vision for collaborative training infrastructure for bioinformatics. Annals of the New York Academy of Sciences, 1387(1), 54-60. 